\title{
Influence of Teacher Delocalization Policy on Pupils' Academic Performance in Public Primary Schools in Loima Sub-County, Turkana County, Kenya
}

\author{
Jane Echwa, Simon Kipkenei, Rispah Wepukhulu \\ Department of Educational Planning and Management, Kibabii University, Kenya
}

\begin{abstract}
The purpose of the study was to establish the effects of teacher delocalization policy on pupils' academic performance in public primary schools in Loima Sub-County, Turkana County, Kenya. The study was guided by descriptive survey research study design. The study targeted a population of 1000 respondents from public primary schools in the sub-county. The sampling technique adopted was simple random sampling to select pupils and teachers while purposive sampling was used in sampling the head teachers. The study adopted a sample size of 110 respondents. A questionnaire was used for data collection. The data was entered, coded, stored and analyzed by the help of Statistical Package Software for Social Sciences. The data was analyzed using percentages and frequencies. The analyzed data was presented in the form of frequency tables, charts, and bar graphs. The findings of the study revealed that teacher delocalization policy harms pupils' learning in the event that effective teachers are replaced by less effective ones.
\end{abstract}

Keywords - Teacher Delocalization, Policy, Pupils, Academic Performance

\section{INTRODUCTION}

M ichaelowa (2002) states that teacher delocalization refers to the indication of movement of the teachers from one work station to another work station. The role of teachers and the teaching profession cannot be overlooked since every nation heavily relies on teachers in the provision of basic education and more specifically in third world countries (Oke \& Ajagbe, 2016). Teachers are depended upon for any success of any school and achievement of pupils'. Teacher's delocalization policy is a problem across the world in the education sector. Schools face rapid shortage not only in Kenya but all over the world with 50 percent of teachers either delocalized from one station to the other within their first five years in service (Thornton, 2004). Previous research has found many factors that lead to high teacher transfers which includes teacher overstay, parental involvement, heavy workload, schools doing equally nothing to retain teachers and poor teacher-student relationship (Barrett, 2009). As such, schools need to come up with policies that may reduce or lessen the teacher delocalization rate in schools. The government should play a role in ensuring that teachers are satisfied in terms of review as well improved working conditions.

Many researchers have considerably put attention to the association of job satisfaction and performance. However, some study findings reveals that job delocalization policy is associated with other factors such as safety conditions and pupils' commitment (Iqbal et al., 2016). However, a lot of literature on teacher delocalization policy shows that satisfied teachers perform much better than unsatisfied teachers. These literatures, further outlines that there are indicators that are associated with teacher delocalization policy which include; decision making leadership styles by administrators, organization behavior and culture which are associated with teachers job satisfaction (Olcum \& Titrek, 2015).

According to Patrick (2007) he suggests five primary factors that affect teachers' workplace delocalization policy which are efficacy, administrative support, students' behaviors, and autonomy and workplace atmosphere. These factors if not handled carefully, does impound on teachers making them not to have good time with their pupils'. As a result of this, some teachers could deliver unsatisfactory work which may affect pupils' performance. Teachers who are not satisfied at the same time may opt to move to schools that do not satisfy the above conditions. Teacher delocalization remains to be the key student success determinants in almost all schools around the world. Among the many factors that influence pupils' performance such as quality of education, teacher satisfaction and social economic factors, the most profound and important factor is job satisfaction (Houtte, 2006).

Teacher delocalization policy has been linked to have an effect on the quality of teaching and pupil performance as a whole, it has also been associated with prediction of withdrawal cognition and this could be very important in the maintenance of stability of the teachers in class (Michaelowa, 2002). Teachers cannot be satisfied until they are motivated. According to Pilarta (2015) on job delocalization policy and teacher's performance in Abra, he suggests that quality education is harbored by lack of proper resources in schools. The study further shows that a hygiene factor plays a very important role in teacher delocalization policy. These factors include; supervision, interpersonal relationship as well as physical appearance of the school and the study concluded that hygiene factors alone did not influence teacher performance in form of pupils' performance. Orodho (2004) urgues that great delocalization policy of teachers means that they justisfy their responsibilities in teaching. At the same 
time, teachers could also be satisfied with behaviours of their supervisors, pay, promotion and working conditions.

\section{RESULTS AND DISCUSSION}

\subsection{Effects of teacher delocalization policy on pupils'} academic performance in KCPE

On whether teacher transfers meant teachers' failure to perform well at school, the findings of the study indicated that (1) $16.0 \%$ of the head teachers were of the view that teacher transfers meant that teachers failed to do well at school, (4) $67.0 \%$ were of the contrary view and (1) $17.0 \%$ were of the view that sometimes teacher transfers arise because of the teacher's failure to do well at school. The findings of the study can be interpreted to mean that teacher transfers did not mean teachers fail to do well at school according to head teachers.

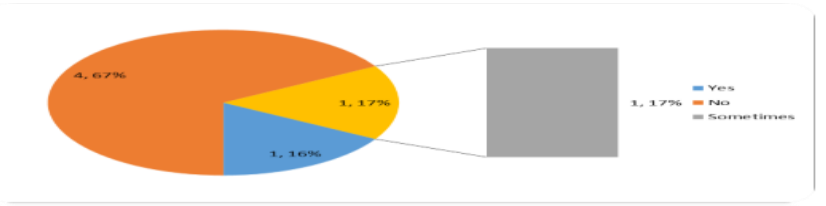

Figure 1. Meaning of teacher transfers (head teachers)

The findings of the study also indicated that (14) $43.8 \%$ of the teachers were of the view that teacher transfers meant teachers' failure to perform well at school, (10)31.3\% were of the contrary view and (8)25.0\% were of the view that sometimes it is caused by teacher's failure to perform well at school. The findings of the study can be interpreted to mean that teacher transfers meant that teachers failed to do well at school according to the response from teachers. This contradicts the opinion of most head teachers in the region.

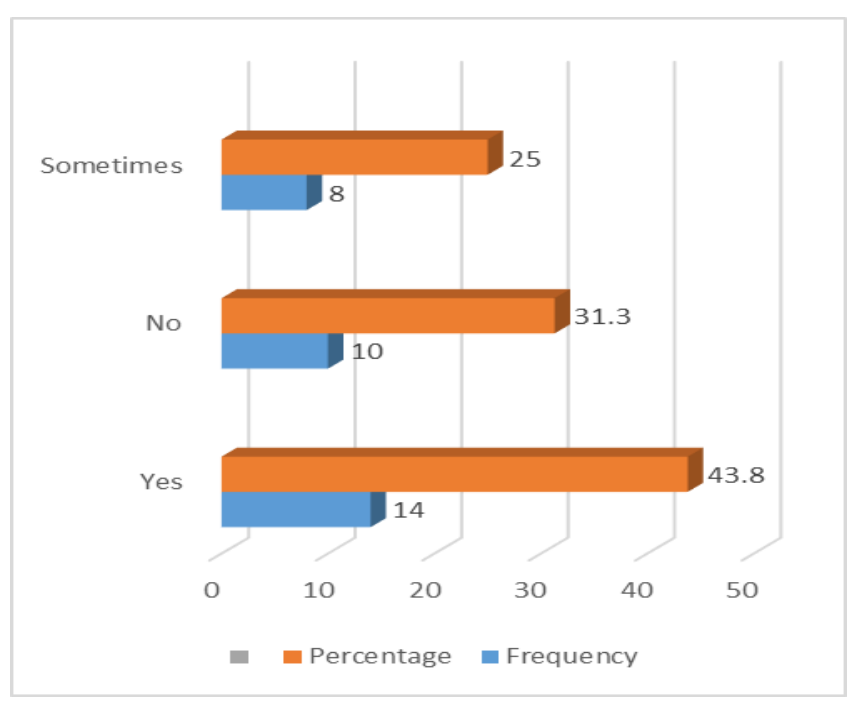

Figure 2. Meaning of teacher transfers (teachers)
The finding further established that when the pupils' were asked whether teacher transfers meant that teachers had failed to do well at school, (24)33.3\% of the pupils' were of the view that teacher transfers meant that teachers failed to perform well, (13) $18.1 \%$ were of the contrary view and (35) $48.6 \%$ were of the view that sometimes failure is the main cause of some transfers. The findings of the study can be interpreted to mean that teacher transfers sometimes cause teachers failure to perform well in the classroom.

Table 1. Meaning of teacher transfers

\begin{tabular}{|c|c|c|}
\hline Teacher Transfers & \multicolumn{2}{|c|}{ Pupils } \\
\hline & Frequency & Percent \\
\hline $10-12$ & 24 & 33.3 \\
\hline $13-14$ & 13 & 18.1 \\
\hline $15-21$ & 35 & 48.6 \\
Total & 72 & 100.0 \\
\hline
\end{tabular}

\subsubsection{Aspects associated with job satisfaction}

On aspects associated with job satisfaction, (1) $16.7 \%$ of head teachers were of the view that job satisfaction was associated with safety conditions, (4)66.7\% of head teachers were of the view that job satisfaction was associated with pupils' commitment and (1)16.7\% of head teachers were of the view that job satisfaction was associated with safety conditions. The findings of the study can be interpreted to mean that job satisfaction was associated with pupils' commitment. Pupils' commitment would mean better KCPE results at the end of the year which may increase job satisfaction and teacher motivation at the place of work.

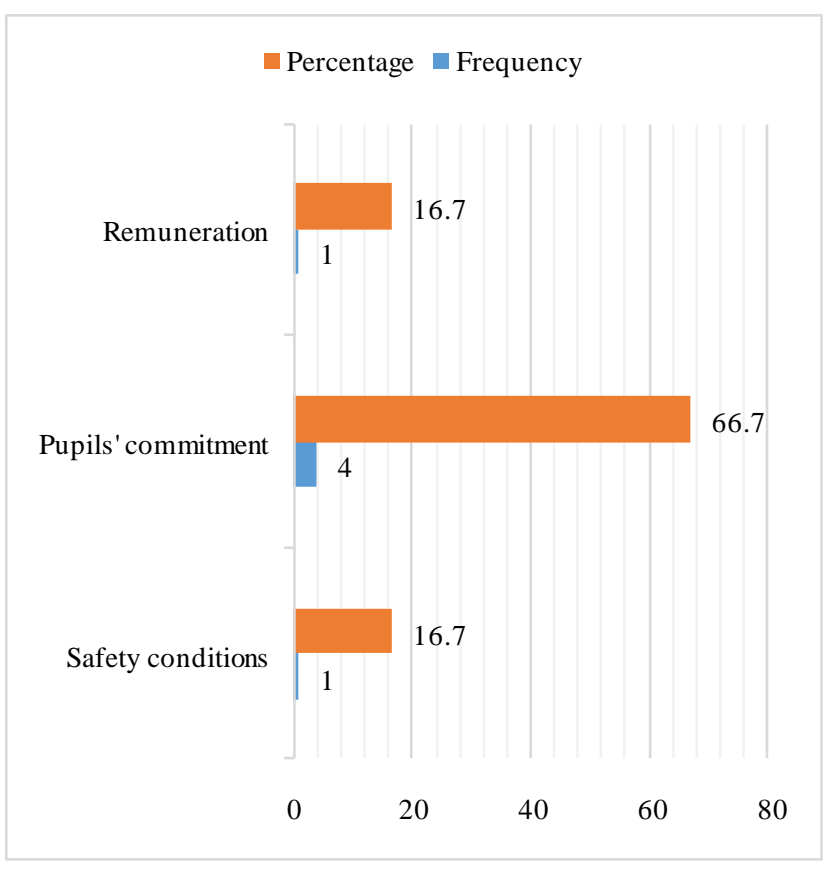

Figure 3. Aspects associated with job satisfaction by head teachers 
On the other hand, the findings on the aspects associated with job satisfaction, (32) $40.6 \%$ of the teachers were of the view that job satisfaction was associated with safety conditions, (4) $9.4 \%$ on pupils' commitment, and (36) $50.0 \%$ was associated with teacher remuneration. The findings of the study can be interpreted to mean that job satisfaction was associated with teacher remuneration. Most teachers in arid areas get extra allowance in terms of hardship.

Table 2. Aspects associated with job satisfaction

\begin{tabular}{|c|c|c|}
\hline Job satisfaction & \multicolumn{2}{|c|}{ Teachers } \\
\hline & Frequency & Percent \\
\hline Safety conditions & 32 & 40.6 \\
\hline Pupils' commitment & 4 & 9.4 \\
\hline Remuneration & 36 & 50.0 \\
Total & 72 & 100.0 \\
\hline
\end{tabular}

2.1.2. Satisfied teachers work better than the unsatisfied counterparts

On whether satisfied teachers work better than unsatisfied counterparts, the findings indicated that (5) $83.3 \%$ of the head teachers were of the view that satisfied teachers work better than unsatisfied counterparts while (1) $16.7 \%$ were of the view that sometimes satisfied teachers work better than the unsatisfied counterparts. The result of the study can be interpreted to mean that satisfied teachers work better than unsatisfied counterparts. As stated earlier in this study, Patrick (2007) suggested five primary factors that affect teachers' workplace delocalization policy which are efficacy, administrative support, students' behaviors, and autonomy and workplace atmosphere. He opined that these factors if not handled carefully, does impound on teachers making them not to have good time with their pupils'. As a result of this, some teachers could deliver unsatisfactory work which may affect pupils' performance. Teachers who are not satisfied at the same time may opt to move to schools that meet their immediate needs.

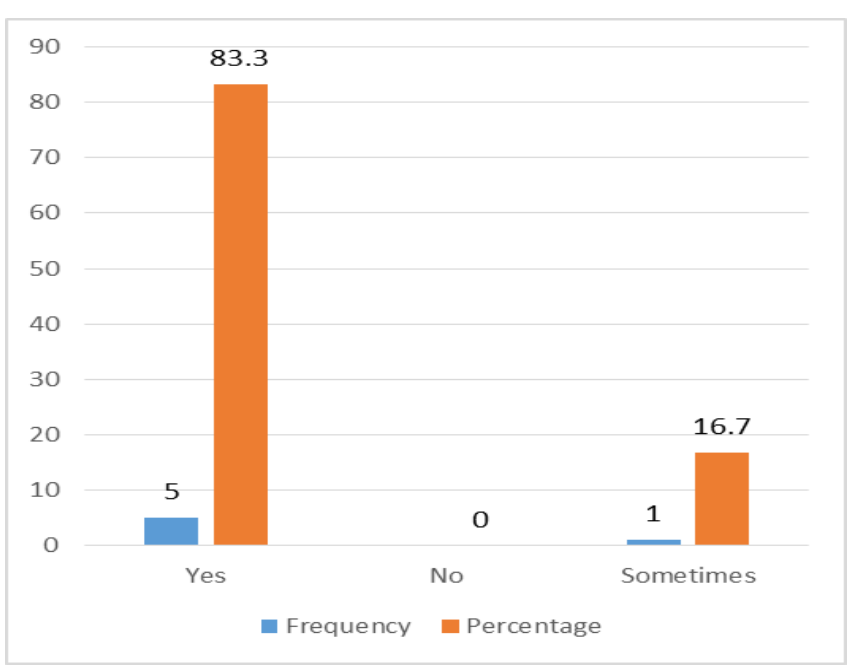

Figure 3. Satisfied teachers work well than unsatisfied counterparts
The findings of the study also showed that (27)68.8\% of teachers were of the view that satisfied teachers work better than the unsatisfied counterparts, (1)3.1\% were not of the view that satisfied teachers work better than the unsatisfied counterparts and (4) $28.1 \%$ were of the view that sometimes satisfied teachers work better than the unsatisfied counterparts. The result of the study can be interpreted to mean that satisfied teachers work better than unsatisfied counterparts

Table 3. Satisfied teachers work well than the unsatisfied counterparts (teachers)

\begin{tabular}{|c|c|c|}
\hline Satisfied Teachers & \multicolumn{2}{|c|}{ Teachers } \\
\hline & Frequency & Percent \\
\hline Yes & 27 & 68.8 \\
\hline No & 1 & 3.1 \\
\hline Sometime & 4 & 28.1 \\
& & $\mathbf{1 0 0 . 0}$ \\
\hline
\end{tabular}

The findings of the study further noted that (54)73.6\% of the pupils were of the view that satisfied teachers work better than the unsatisfied counterparts, (6) $8.3 \%$ were not of the view that satisfied teachers work better than the unsatisfied counterparts, and (12) $17.1 \%$ were of the view that sometimes satisfied teachers work better than the unsatisfied counterparts. The findings of the study can be interpreted to mean that satisfied teachers work better than the unsatisfied counterparts.

Table 4. Satisfied teachers' work well than the unsatisfied counterparts

\begin{tabular}{|c|c|c|}
\hline $\begin{array}{c}\text { Satisfied } \\
\text { Teachers }\end{array}$ & \multicolumn{2}{|c|}{ Pupils } \\
\hline & Frequency & Percent \\
\hline Yes & 54 & 73.6 \\
\hline No & 6 & 8.3 \\
\hline Sometime & 12 & 17.1 \\
Total & $\mathbf{7 2}$ & $\mathbf{1 0 0 . 0}$ \\
\hline
\end{tabular}

2.1.3. Teachers who are not satisfied may opt to move to other schools

When asked whether teachers who are not satisfied teachers opting to move to other schools, and the findings indicated that (5)83.3\% of the head teachers were of the opinion that teachers who are not satisfied may opt to move to other schools whereas (1) $16.7 \%$ were of the idea that sometimes teachers who are not satisfied may opt to move to other schools. The result of the study can be interpreted to mean that teachers who are not satisfied opt to move to other schools. 


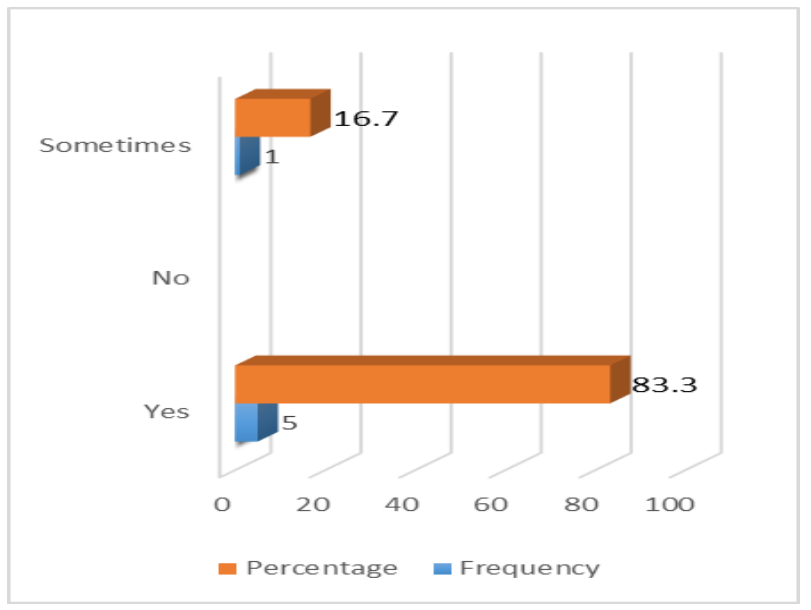

Figure 1. Teachers who are not satisfied may opt to move to other schools (head teachers)

The findings also indicated that (22)68.8\% of teachers were of the view that teachers who are not satisfied may opt to move to other schools, (4) $12.5 \%$ were not of the idea and (6)18.8\% were of the view that sometimes teachers who are not satisfied may opt to move to other schools.

Table 5. Teachers who are not satisfied may opt to move to other schools (teachers)

\begin{tabular}{|c|c|c|}
\hline $\begin{array}{c}\text { Satisfied } \\
\text { Teachers }\end{array}$ & \multicolumn{2}{|c|}{ Teachers } \\
\hline & Frequency & Percent \\
\hline Yes & 22 & 68.8 \\
\hline No & 4 & 12.5 \\
\hline $\begin{array}{c}\text { Sometime } \\
\text { Total }\end{array}$ & 6 & 18.8 \\
\hline
\end{tabular}

The findings further showed that (56)77.8\% of the pupils were of the view that teachers who are not satisfied may opt to move to other schools, (2) $2.8 \%$ were not of the view that teachers who are not satisfied teachers may opt to move to other schools and (14)19.4\% were of the view that sometimes teachers who are not satisfied teachers may opt to move to other schools. The findings of the study can be interpreted to mean that teachers who not satisfied may opt to move to other schools.

Table 6. Teachers who are not satisfied may opt to move to other schools (pupils')

\begin{tabular}{|c|c|c|}
\hline Satisfied Teachers & \multicolumn{2}{|c|}{ Pupils' } \\
\hline & Frequency & Percent \\
\hline Yes & 56 & 77.8 \\
\hline No & 2 & 2.8 \\
\hline Sometime & 14 & 19.4 \\
Total & $\mathbf{7 2}$ & $\mathbf{1 0 0 . 0}$ \\
\hline
\end{tabular}

\subsubsection{Teacher satisfaction is the key to pupils' success}

The findings on whether teacher satisfaction is the key to pupils' success, (21)67.0\% of the head teachers were of the view that teacher satisfaction is the key to pupils' success while (11)33.0\% were of the view that sometimes it does. The result of the study can be interpreted to mean that teacher satisfaction is the key to pupils' success.

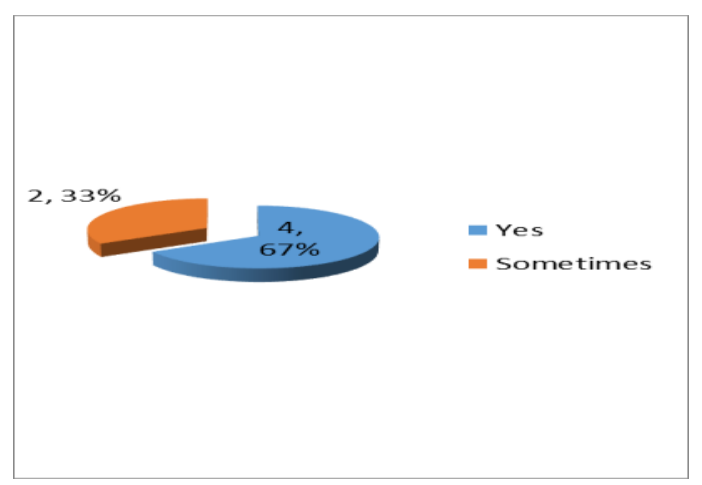

Figure 5. The association of job satisfaction with the quality of teachers and pupils' performance

Table 7. Association of job satisfaction with the quality of teachers and pupils' performance

\begin{tabular}{|c|c|c|}
\hline Job satisfaction & \multicolumn{2}{|c|}{ Teachers } \\
\hline & Frequency & Percent \\
\hline Yes & 28 & 87.4 \\
\hline No & 2 & 6.3 \\
\hline Sometimes & 2 & 6.3 \\
Total & 32 & 100.0 \\
\hline
\end{tabular}

The findings further indicated that (36)54.2\% of the pupils' were of the idea that job satisfaction was associated with the quality of teaching and pupils' performance, (6)8.3\% were not of the view and (27)37.5\% were of the view that sometimes. The findings of the study can be interpreted to mean that job satisfaction was associated with the quality of teaching and pupils' performance. This is due to the fact that when teachers are satisfied, they also try their best to invest in their pupils' as such boosting their pupils' academic performance.

Table 8. Association of job satisfaction with the quality of teachers and pupils' performance

\begin{tabular}{|c|c|c|}
\hline Job satisfaction & \multicolumn{2}{|c|}{ Pupils' } \\
\hline & Frequency & Percent \\
\hline Yes & 36 & 54.2 \\
\hline No & 6 & 8.3 \\
\hline Sometimes & 27 & 37.5 \\
Total & 72 & 100.0 \\
\hline
\end{tabular}

Table 9. Teacher satisfaction is the key to pupils'

\begin{tabular}{|c|c|c|}
\hline Pupils' success & \multicolumn{2}{|c|}{ Head Teachers } \\
\hline & Frequency & Percent \\
\hline Yes & 24 & 75.0 \\
\hline No & 2 & 6.3 \\
\hline Sometimes & 6 & 18.7 \\
Total & $\mathbf{3 2}$ & $\mathbf{1 0 0 . 0}$ \\
\hline
\end{tabular}

The findings also showed that (24)75.0\% of the teachers were of the idea that teacher satisfaction is the key to the pupils' 
success, (2)6.3\% were not of the view and (6)18.7\% were of the view that sometimes it does. The result implies that teacher satisfaction is the key to the pupils'.

Figure 6. Satisfied teachers work better than their unsatisfied counter parts (pupils')

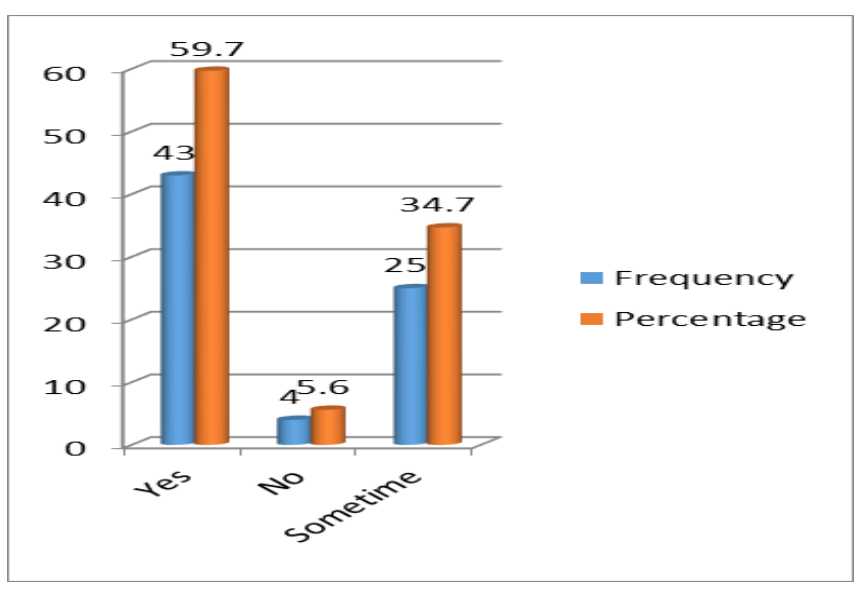

The findings further showed that (43)59.7\% of the pupils' were of the view that teacher satisfaction was key to pupils' success, (4)5.6\% were not of the view and (25)34.7\% were of the view that it does sometime. The findings of the study can be interpreted to mean that teacher satisfaction is the key to pupils' success.

\subsubsection{Motivation is the key to teacher satisfaction}

The findings of the study indicated that (4)67.0\% of head teachers were of the view that motivation was key to teacher satisfaction, and (2)33.0\% were not of the same view. The result of the study can be interpreted to mean that motivation is the key to teacher satisfaction. When teachers are recognized, given incentives and appreciation, then they feel rewarded for their effort

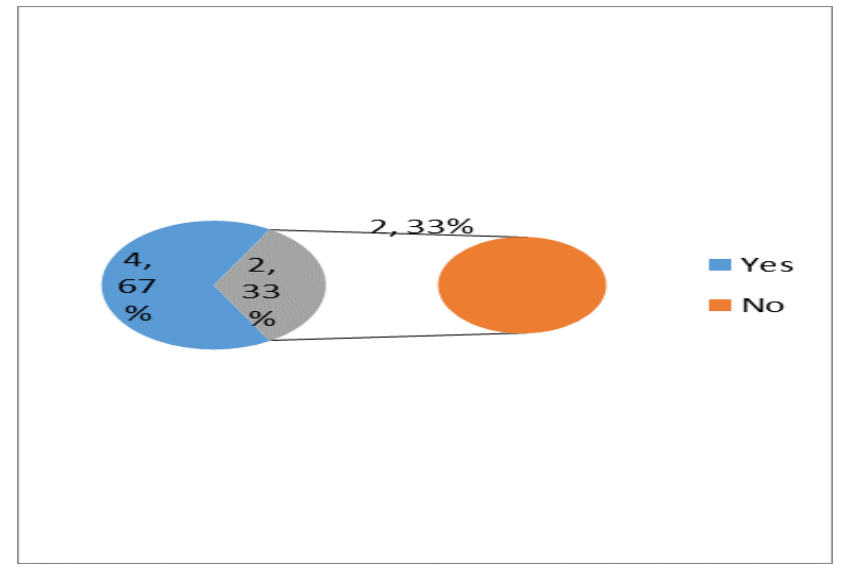

Figure 7. Motivation is the key to teacher satisfaction (head teachers)

The findings also showed that (26)81.3\% of the teachers were of the view that motivation was the key to teacher satisfaction, (3) $9.4 \%$ were not of the view and (3)9.4\% were of the view that sometimes motivation was the key to teacher satisfaction. The findings of the study can be interpreted to mean that motivation was the key to teacher satisfaction. Teacher motivation is critical for pupils learning outcomes. According to Mendez (2011) teacher attitude is the dominant factor explaining teacher and school performance in their evaluation of a basic education project in Guatemala. In East Africa, Anderson (2001) reports that teachers' motivation is a key factor in enhancing teachers' commitment which in turn is an important determinant of learning outcomes. It therefore follows that high teacher motivation leads to positive educational outcomes.

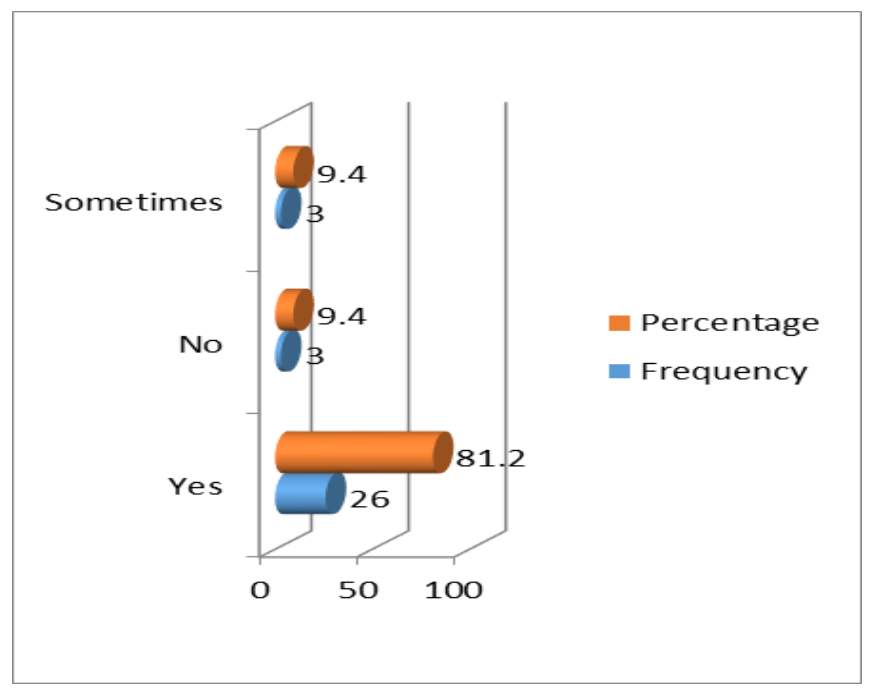

Figure 8. Motivation as the key factor for the success of pupils' (pupils')

\subsubsection{The factors that play an important role in teacher delocalization}

On whether supervision play an important role in teacher delocalization, (1)16.7\% of the head teachers disagreed that supervision played an important role in teacher delocalization, (3)50.0\% agreed and (2)33.3\% strongly agreed that supervision play an important role in teacher delocalization. The finding of the study can be interpreted to mean that supervision played an important role in teacher delocalization.

The result also revealed that (4)12.5\% of the teachers strongly disagreed that supervision played an important role in teacher transfers, (4)12.5\% disagreed, (7)21.9\% were undecided, (8) $25.0 \%$ agreed and (9)28.1\% strongly agreed. The findings of the study can be interpreted to mean that supervision was an important role in teacher delocalization.

On whether interpersonal relationship play an important role in teacher delocalization, (1) $16.7 \%$ of head teachers disagreed, (1) $16.7 \%$ were undecided and (4)66.7\% agreed that interpersonal relationship played an important role in teacher delocalization. The result of the study can be interpreted to mean that interpersonal relationship plays an important role in teacher delocalization.

The findings further revealed that (11)34.4\% of the teachers strongly disagreed that interpersonal relationship played an important role in teacher transfer, (6)15.6\% disagreed, 
(1) $3.1 \%$ were undecided, (21) $65.6 \%$ agreed and (4) $12.5 \%$ strongly agreed. The findings of the study can be interpreted to mean that interpersonal relationship played an important role in teacher delocalization.

When asked whether the appearance of the school as a hygiene factor played an important role in teacher delocalization, the findings indicated that (2)33.3\% of the head teachers strongly disagreed with the opinion, (1) $16.7 \%$ disagreed, (2)33.3\% agreed and (1)16.7\% strongly agreed.

On the other hand, when the teachers were asked similar question, (11)34.4\% strongly agreed, (6)18.8\% disagreed, (6) $18.8 \%$ were undecided, (5) $15.6 \%$ agreed and (4) $12.5 \%$ strongly agreed. The findings of the study can be interpreted to mean that the appearance of the school may do some extent play or not play an important role in teacher delocalization

\subsubsection{Discussion on the extent at which teacher delocalization policy affects pupils' performance in primary schools}

This section sought to assess the extent at which teacher delocalization policy affects pupils' performance in public primary schools in Turkana County, Kenya. On meaning of teacher transfers, the finding revealed that (22)68.8\% of teachers were of view that teacher transfers meant that teachers failed to do well at school. If they perform well, then pupils' performance would be affected positively, on the other hand, if they failed, then it means that the fact that teachers are transferred would obviously affect pupils' performance in some ways. The findings of the study do not correspond with the study by Michaelowa (2002) which states that teacher transfers refer to the indication of movement of the teachers from one work station to another work station.

On whether job satisfaction in teachers affected pupils' performance, the result revealed that satisfied teachers work better than the unsatisfied counterparts as evidenced by (5) $83.3 \%$ of the head teachers. This finding relates with the study by Olcum \& Titrek (2015) which states that satisfied teachers perform much better than unsatisfied teachers. This result also corresponds with the study by Mampane (2012) which asserts that teachers who are dissatified their brain is drained hence they cannot be of help to their pupils' and this may affect the pupils' performance.

On whether teachers who are unsatisfied may opt to move to other schools, the result revealed that teachers who are unsatisfied may opt to move to other schools. This findings relates with the study by Patrick (2007) who suggests that factors such as adminstrative support, students' behavior and auotonomy and work place atsmophere could make teachers to deliver unsatisfactory work thereby affecting pupils' performance when they move in the mid of the academic calender.

On whether teacher satisfaction was the key to pupils' success, the findings established that teacher satisfaction was the key to pupils' success. This study relates with the study by
Houtte (2006) who argues that among the many factors that influence pupils' performance is teacher satisfaction. The findings also established that satisfaction of teachers was associated with affecting the quality of teachings and pupils' performance as evidenced by (28) $87.5 \%$ of teachers. The study corresponds with the study by Michaelowa (2002) which states that job satisfaction was associated with teacher delocalization which affects the quality of teaching and pupils' performance.

On whether motivation was the key to teacher satisfaction, the findings noted that that motivation was the key to teacher satisfaction as indicated by (26)81.3\% of teachers. This finding resembles with the study by Michaelowa (2002) who states that teachers cannot be satisfied until they are motivated. The result of the study further noted that satisfied teachers work better than unsatisfied counterparts as evidenced by (27)83.3\% of teachers.

The findings further revealed that supervision as factors play, interpersonal relationship and while school appearance did or did not play an important role in teacher delocalization. This finding on one hand corresponds fully and on the other does not fully correspond with the study by Pilarta (2015) who suggests that a hygiene factor plays a very important role in teacher delocalization policy.

\section{CONCLUSION}

Based on the results of the study, it can be concluded that teacher delocalization policy affects pupils' performance in primary schools where teachers who felt not satisfied opted to move to other schools and this ended up having an effect on pupils' performance. However, satisfied teachers worked better thereby contributing positively to the success of pupils' performance academically and they were retained in school for long.

\section{RECOMMENDATION}

The study reccommended that the Teachers Service Commission should swiftly carry out appropriate replacement once a teacher is transferred to another school to avoid interruptions of teaching/ learning process

\section{REFERENCES}

[1] Iqbal, A., Aziz, F., Khan, T., \& Ali, S. (2016). Relationship between Teachers' Job Satisfaction and Students Academic Performance. Eurasian Journal of Educational Research(65), 335344.

[2] Mampane, P. M. (2012). The Teacher Turnover Criisis. Evidence from South Africa. Business Education and Accreditation, 4(2).

[3] Michaelowa, K. (2002). Teacher Job Satisfaction Student Achievement, and the Cost of Primary Education in Frachophone Sub-Saharan Africa. Hamburg: Hamburg Institute of International Economics

[4] Olcum, D., \& Titrek, O. (2015). The Effect of School Adminsitrators' Decision-Making Styles on Teachers Job Satisfaction. American Journal of Educational Research , 19261046. 